\title{
IMPLEMENTASI KEBIJAKAN PENGELOLAAN SAMPAH DI DINAS LINGKUNGAN HIDUP KOTA TASIKMALAYA (Studi di Kecamatan Indihiang Kota Tasikmalaya)
}

\section{Muhammad Ibrahim Sahupala}

Sekolah Tinggi Ilmu Sosial dan Ilmu Politik ( STISIP ) Tasikmalaya

Email: bram.patty88@gmail.com

\section{Abstract}

Waste management that often occurs as a result of people's behavior and lifestyle tends to be lack of awareness, so that people throw littering. The theory of policy implementation from Van Meter and Van Horn, Policy Implementation will be successful and whether implemented is determined by the size and purpose of the policy, sources of wisdom, characteristics or nature of the implementing agency / agency, communication between related organizations and implementation activities, The attitude of the implementers, as well as the economic, social and political environment. The results showed that the implementation of the Waste Management policy at the Department of the Environment was carried out. open communication to the public by socializing these regulations. The Office of the Environment coordinates with other agencies. conduct supervision and guidance to implementers in the field and provide adequate infrastructure facilities to manage waste, but the Tasikmalaya City Environmental Agency has not been intense in doing so due to budget constraints

Keywords: Policy Implementation, Communication, Coordination,Disposition

Abstrak

Pengelolaan sampah yang sering terjadi akibat dari perilaku dan pola hidup masyarakat cenderung masih belum adanya kesadaran, sehingga masyarakat membuang sampah sembarangan. Teori implementasi kebijakan dari Van Meter dan Van Horn, Implementasi Kebijakan akan berhasil dan tidaknya di implementasikan ditentukan oleh Ukuran dan tujuan kebijaksanaan, Sumbersumber kebijaksanaan, Karakteristik Lembaga penyelenggara, Hubungan diantara Organisasi yang berhubungan dan Aktivitas-aktivitas penyelenggara, perbuatan anggota penyelenggara, dan Lingkungan ekonomi, sosial serta politik. Hasil penelitian menunjukkan bahwa implementasi kebijakan Pengelolaan Sampah di Dinas Lingkungan Hidup telah dilaksanakan. komunikasi secara terbuka kepada masyarakat dengan mensosialisasikan peratauran tersebut. Dinas Lingkungan Hidup berkoordinasi dengan instansi lainnya. melakukan pengawasan dan pembinaan kepada para penyelenggara di lapangan dan memberikan fasilitas sarana prasarana yang cukup untuk mengelola sampah tetapi Dinas Lingkungan Hidup Kota Tasikmalaya belum intens dalam melakukannya karna terbatasnya anggaran.

Kata kunci : Implementasi Kebijakan, Komunikasi, Koordinasi, Disposisi. 


\section{Pendahuluan}

Lingkungan selalu ada di antara manusia, sejak dari manusia lahir sampai manusia mati, Oleh karena itu adanya keterkaitan antara keduanya bisa diartikan lingkungan bisa mempengaruhi manusia serta manusia mempengaruhi lingkungan (Muslih, 2016).

Sampah bukan hanya menjadi isu lingkungan saja, tetapi sudah menjadi isu multidimensi karna apabila pengelolaan sampah ini tidak baik maka akan menyebabkan bencana banjir, mewabahnya penyakit cikungunya, demam berdarah dengue (DBD) dan lain sebagainya.

Permasalahan sampah merupakan permasalahan yang dihadapi manusia dalam kehidupan sehari-hari, hal ini terjadi karena pada dasarnya manusia hidup untuk memenuhi kebutuhan kehidupannya maka selama itu pula sampah akan terus dihasilkan. Kondisi ini membuat sampah menjadi hal yang tidak mungkin dapat dihilangkan keberadaannya dan akan terus muncul selama kehidupan manusia terus berlangsung di dunia ini. Masalah sampah di daerah berkembang menjadi masalah yang cukup serius dan memerlukan perhatian khusus. Selanjutnya pengelolaan sampah pada manajemen 3P (Pengumpulan, Pengangkutan, dan Penimbunan di TPA) diubah dengan disahkannya Undang-Undang Republik Indonesia Nomor 18 Tahun 2008 tentang Pengelolaan Sampah. Pasal 8 mengamanatkan proses pemilahan sampah harus segera dilaksanakan oleh semua unsur masyarakat pada semua aktivitas. Sebagaimana diperkuat dengan Peraturan Daerah Nomor 7 Tahun 2012 Tentang Pengelolaan Sampah di Kota Tasikmalaya.

Kenyataan di lapangan, Implementasi Kebijakan Peraturan Daerah Nomor 7 Tahun 2012 Tentang Pengelolaan Sampah di Kota Tasikmalaya belum berjalan sesuai dengan apa yang diharapkan, dengan adanya permasalahan yang terlihat, Dinas Lingkungan Hidup melakukan komunikasi dengan cara mensosialisasikan Peraturan Daerah Nomor 7 Tahun 2012 kepada Ketua RW, RT, tokoh agama, tokoh pemuda dan masyarakat ditiap-tiap Kelurahan di wilayah Kecamatan Indihiang, tetapi kenyataan di lapangan tidak semua masyarakat Kecamatan Indihiang mengetahui adanya Peraturan Daerah Nomor 7 Tahun 2012 Tentang Pengelolaan Sampah dan masyarakat juga seolah apriori terhadap permasalahan sampah ini karna walaupun sudah disosialisasikan dan bahkan ketua RT sudah mengingatkan, tetapi masyarakat tetap saja membuang sampahnya ke parit dan sungai yang berakibat banjir.

Dinas Lingkungan Hidup membuat jadwal pengangkutan sampah tetapi sikap pelaksana dalam pelaksanaannya, masih terlambatnya pengangkutan sampah tidak sesuai jadwal dan sudah melaksanakan koordinasi dengan Organisasi Perangkat Daerah terkait tetapi dilapangan belum adanya sanksi terhadap pelanggaran yang membuang sampah sembarangan dan masih banyaknya yang membuang sampah ke parit dan sungai. 


\section{Metode Penelitian}

Metode penelitian yang dipakai yaitu melalui pendekatan kualitatif studi kasus dengan metode analisis deskriptif. Pendekatan kualitatif dilakukan agar penelitian lebih komprehensif dan apa adanya bagaimana implementasi kebijakan. Metode ini digunakan untuk memotret kondisi dilapangan dan menemukan fakta dengan interpretasi dan melukiskan secara akurat sifat dari beberapa kejadian kelompok serta perorangan yang berawal dari hasil penemuan penelitian.

Metode penelitian kualitatif bisa disebut juga metode penelitian naturalistik karena penelitiannya dilaksanakan kepada keadaan yang alamiah artinya penelitian ini dilakukan langsung turun kelapangan. Seperti yang dikatan (Hidayat \& Ahza, n.d.) dalam buku Metode Penelitian Kuantitatif Kualitatif dan R\&D metode penelititan kualitatif adalah metode penelitian yang berlandaskan pada filsafat postpositivisme, digunakan untuk meneliti pada kondisi obyek yang alamiah.

\section{Hasil dan Pembahasan}

Upaya Pemerintah Kota Tasikmalaya melalui Dinas Lingkungan Hidup melaksanakan Peraturan Daerah Nomor 7 Tahun 2012 Tentang Pengelolaan Sampah ke tiap-tiap Kelurahan yang ada di Kecamatan Indihiang. Upaya yang dilaksanakan seperti mensosialisasikan tentang pengelolaan sampah, upaya peremajaan armada pengangkut sampah, penambahan SDM, penambahan TPSS, peningkatan keahlian pegawai dalam pengelolaan sampah, pembinaan petugas pengangkut sampah, berkoordinasi dengan Organisasi Perangkat Daerah yang terkait, contoh dengan BAPPEDA.

Kebijakan Publik di ciptakan oleh pemerintah melalui proses kerjasama dengan masyarakat untuk menciptakan kesejahteraan dan keteraturan hidup di suatu Negara, sedangkan proses untuk pembuatan kebijakan itu adalah formulasi, implementasi dan evaluasi. Dalam jurnal ini peneliti menitik beratkan pada pembahasan tentang bagaimana implementasi kebijakan Peraturan Daerah Nomor 7 tahun 2012 tantang pengelolaan sampah di Kota Tasikmalaya agar dapat di realisasikan.

\section{Ukuran dan tujuan kebijaksanaan}

Kinerja implementasi kebijakan dapat diukur tingkat keberhasilannya dari ukuran serta tujuan kebijakan yang sifatnya nyata dengan sosio-kultur yang ada di tingkat penyelenggara kebijakan. Pada saat ukuran serta tujuan kebijakan terlalu ideal (utopis), oleh karena akan sulit direalisasikan (Agustino, 2006) (Sulaeman et al., 1998) menyatakan untuk mengukur kinerja pelaksanaan kebijakan pastinya memperjelaskan standar serta tujuan khusus yang mesti diperoleh oleh para penyelenggara kebijakan, kinerja kebijakan pada umunya menggambarkan penilaian terhadap tingkat ketercapaian standar serta sasaran itu.

Penafsiran mengenai maksud umum dari suatu standar serta tujuan kebijakan itu penting. Pelaksanaan kebijakan yang berhasil, bisa juga gagal (frustated) pada saat para penyelenggara (officials), tidak seutuhnya sadar kepada standar serta tujuan kebijakan. Standar dan tujuan kebijakan mempunyai kaitan erat dengan disposisi para penyelenggara (implementors). Arah disposisi para penyelenggara 
(implementors) terhadap standar serta tujuan kebijakan pula merupakan perihal yang "crucial". Implementors bisa jadi gagal dalam melakukan kebijakan, disebabkan mereka melawan serta tidak paham apa yang menjadi sasaran dalam kebijakan (Van Meter \& Van Horn, 1975)

\section{Sumber-sumber Kebijaksanaan}

Sumber kebijakan dalam pengelolan sampah diatur oleh Negara dengan Undang-Undang Republik Indonesia Nomor 18 Tahun 2008 tentang Pengelolaan Sampah diperkuat oleh pemerintahan Kota Tasikmalya dengan Peraturan Daerah Nomor 7 Tahun 2012 Tentang Pengelolaan Sampah di Kota Tasikmalaya Untuk selanjutnya Pemerintah Kota Tasikmalaya dalam hal ini Dinas Lingkungan Hidup memperjelas dengan membuat standart operation procedur (SOP).

Standard Operating Prosedures (SOP) penyelenggara kebijakan, sudah mempermudah para pelaku kebijakan untuk mengetahui, mengartikan serta memahami makna terhadap hasil yang dilakukan oleh pelaku kebijakan. Salah satu isi dari standart operation procedur (SOP) yaitu:

1. Tata cara membuang sampah saat ini yang dilakukan oleh warga masyarakat Kecamatan Indihiang dengan dua pola yaitu pola individual langsung dan pola individual tidak langsung.

a. Pola individual langsung adalah pengangkutan sampah yang langsung pada sumbernya atau pemukiman menggunakan dump truck. Sampah yang berada dipemukiman dibawa oleh petugas kebersihan dan dikumpulkan di truk sampah. Setelah sampah terkumpul di truk maka dibuang langsung ke Tempat Pembuangan Akhir (TPA). Sistem pengangkutan sampah pola individual langsung digunakan apabila akses jalan menuju sumber sampah atau pemukiman bisa dilewati oleh armada pengangkut sampah.Seperti gambar di bawah ini yang dilakukan oleh pengangkut sampah menggunakan mobil armada dump truck dengan petugas pengangkutnya 5 orang.

b. Pola individual tidak langsung adalah petugas yang dibentuk oleh RT/RW mengangkut sampah dari sumber dan pemukiman lalu dikumpulkan di Tempat Pembuangan Sampah Sementara (TPSS) dan setelah itu diangkut oleh petugas kebersihan menggunakan truk amroll ke Tempat Pembuangan Akhir (TPA). Sistem pengangkutan sampah pola individual tidak langsung digunakan pada pemukiman padat. Karena akses jalan tidak bisa dilalui oleh armada pengangkut sampah.

\section{Ciri-ciri atau sifat Badan/Instansi pelaksana}

Ciri-ciri atau sifat Badan ini akan mempengaruhi terimplementasinya suatu kebijakan, dalam hal ini instansi dari pelaksana kebijakan pengolahan sampah di kota Tasikmalaya adalah Dinas Lingkungan hidup. para pelaksana yang dibawahnya yaitu Bidang Pengelolaan Persampahan, seksi sarana prasarana persampahan, seksi peningkatan kapasitas dan kemitraan kebersihan sudah berpendidikan minimal S1 tetapi memang struktur yang terbawah yaitu tim 
pengambilan sampah dan penyapu jalanan tidak diharuskan berpendidikan S1 karna itu hanya di bidang teknis.

Para pelaksana dalam hal ini UPS-UPS bagian di Kecamatan Indihiang belum optimal dalam melaksanakan tugas dan tanggung jawabnya terhadap tugas karna kurangnya pengawasan dan pembinaannya oleh Dinas lingkungan Hidup.

\section{Komunikasi antar organisasi terkait dan kegiatan-kegiatan pelaksanaan}

Supaya kebijakan publik dapat dilakukan dengan efektif, menurut (Widodo, 2007) segala sesuatu yang menjadi standar tujuan mesti dimengerti oleh (implementors). Yang memiliki beban terhadap perolehan standar serta tujuan kebijakan, oleh karenanya standar serta tujuan harus ada hubungan terhadap para penyelenggara. Komunikasi dalam konteks penyampaian informasi terhadap para penyelenggara kebijakan mengenai apa yang menjadi standar serta tujuan mesti stabil serta seragam (consistency and uniformity) dari bermacam-macam sumber informasi yang di peroleh.

Apabila tidak ada kejelasan, kestabilan serta kesamaan kepada suatu standardan tujuan dari kebijakan itu, oleh karenanya yang menjadi standar serta tujuan kebijakan tidak mudah digapai. Adanya penjelasaan itu, para penyelenggara kebijakan bisa memahami apa yang diinginkannya serta paham apa yang akan dilakukan. Dalam suatu organisasi publik, pemerintah daerah contohnya, komunikasi kadang-kadang dilakukan adalah cara yang tidak mudah serta rumit. Proses pentransferan berita kebawah di dalam organisasi serta dari suatu organisasi ke organisasi lain, serta ke komunikator lain, sering terjadi ganguan (distortion) baik yang dilakukan terencana ataupun tidak terencana. Apabila asal muasal dari sumber komunikasi berbeda memberikan interprestasi yang tidak sama (inconsistent) suatu standar serta tujuan, atau sumber informasi sama menyerahkan interprestasi yang komplit dengan perselisihan (conflicting), Oleh karena itu pada suatu saat penyelenggara kebijakan akan menemukan suatu hal yang lebih sulit untuk melakukan suatu kebijakan secara sungguh-sungguh.

Dengan demikian, peluang pelaksanaan kebijakan yang ampuh, banyak ditetapkan oleh komunikasi terhadap para penyelenggara kebijakan dengan cara teliti serta stabil (accuracy and consistency) (Van Mater dan Varn Horn, dalam Widodo 1974). Dilain hal, koordinasi adalah mekanisme yang ampuh dalam pelaksanaan kebijakan. Semakin baik koordinasi komunikasi di antara aspek-aspek yang ada di dalam pelaksanaan kebijakan, oleh karenanya kesalahan akan semakin sedikit dilihat, demikian kebalikannya. Faktor hambatannya dalam sosialisasi Peraturan Daerah Nomor 7 Tahun 2012 Tentang Pengelolaan Sampah disampaikan oleh bawahan, pimpinan hanya menerima laporannya, tidak sampainya informasi Peraturan Daerah tersebut kepada masyarakat padahal Dinas Lingkungan Hidup telah menyampaikan peraturan daerah tersebut kepada Ketua RT dan Ketua RW akibatnya masyarakat tidak mengetahui peraturan daerah itu, berarti para Ketua RT dan RW tidak menyampaikan lagi kepada masyarakat tentang Peraturan Daerah tersebut. 
Komunikasi yang dilaksanakan Dinas Lingkungan Hidup Kota Tasikmalaya selama ini menggunakan komunikasi satu arah dianggap belum optimal, ini bisa dilihat dari adanya sebagian masyarakat Kecamatan Indihiang belum mengetahui adanya Peraturan Daerah Nomor 7 Tahun 2012 Tentang Pengelolaan Sampah, menurut (Widodo, 2007). Supaya kebijakan publik dapat dilakukan dengan efektif maka para pelaksana harus mengetahui apa yang menjadi standar dan tujuan oleh para individu (implementors). Yang bertanggung jawab atas pencapaian standar dan tujuan kebijakan, karena itu standar dan tujuan harus dikomunikasikan kepada para pelaksana. Komunikasi dalam kerangka penyampaian informasi kepada para pelaksanaan kebijakan tentang apa yang menjadi standar dan tujuan harus konsisten dan seragam (consistency and uniformity) dari berbagai sumber informasi Selanjutnya belum optimalnya koordinasi dengan SATPOL PP karena instansi ini penegakan Peraturan Daerah itu berupa sanksi, hambatan lainnya belum optimalnya petugas pengangkut sampah mematuhi SOP, dikarenakan tidak semua petugas lapangan memahami aturan yang telah ditetapkan.

\section{Sikap Para Pelaksana}

Menurut pendapat (Nasution \& Agustinus, 2006): "sikap penerimaan atau penolakan dari agen pelaksana kebijakan sangat mempengaruhi keberhasilan atau kegagalan implementasi kebijakan publik. Hal ini sangat mungkin terjadi karena kebijakan yang dilaksanakan bukanlah hasil formulasi warga setempat yang mengenal betul permasalahan dan persoalan yang mereka rasakan. Tetapi kebijakan publik biasanya bersifat top down yang sangat mungkin para pengambil keputusan tidak mengetahui bahkan tak mampu menyentuh kebutuhan, keinginan atau permasalahan yang harus diselesaikan.

Sikap mereka itu dipengaruhi oleh pandangannya terhadap suatu kebijakan dan cara melihat pengaruh kebijakan itu terhadap kepentingan-kepentingan organisasinya dan kepentingan-kepentingan pribadinya. (Van Meter \& Van Horn, 1975) menjelaskan disposisi, bahwa implementasi kebijakan diawali penyaringan (befiltered) lebih dahulu melalui persepsi dari pelaksana (implementors) dalam batas mana kebijakan itu dilaksanakan. Terdapat tiga macam elemen respon yang dapat mempengaruhi kemampuan dan kemauannya untuk melaksanakan suatu kebijakan, antara lain terdiri dari pertama, pengetahuan (cognition), pemahaman dan pendalaman (comprehension and understanding) terhadap kebijakan, kedua, arah respon mereka apakah menerima, netral atau menolak (acceptance, neutrality, and rejection), dan ketiga, intensitas terhadap kebijakan.

Pemahaman tentang maksud umum dari suatu standar dan tujuan kebijakan adalah penting. Karena, bagaimanapun juga implementasi kebijakan yang berhasil, bisa jadi gagal (frustated) ketika para pelaksana (officials), tidak sepenuhnya menyadari terhadap standar dan tujuan kebijakan. Arah disposisi para pelaksana (implementors) terhadap standar dan tujuan kebijakan. Arah disposisi para pelaksana (implementors) terhadap standar dan tujuan kebijakan juga merupakan hal yang "crucial”. Implementors mungkin bisa jadi gagal dalam melaksanakan 
kebijakan, dikarenakan mereka menolak apa yang menjadi tujuan suatu kebijakan (Van Meter \& Van Horn, 1975).

Dinas Lingkungan Hidup dalam mengimplementasikannya menemui hambatan yaitu sikap para pelaksana di lapangan belum optimal melaksanakan tugas yang menjadi tanggungjawabnya, untuk UPS-UPS yang tidak berjalan dengan baik kurangnya pembinaan dan pengawasan dari Dinas Lingkungan Hidup.

\section{Lingkungan Ekonomi, Sosial dan Politik}

Perihal terakhir yang harus dilihat supaya bisa menilai kinerja pelaksanaan kebijakan ialah sejauh mana lingkungan luar ikut mendukung keberhasilan kebijakan publik. Lingkungan sosial, ekonomi serta politik yang tidak mendukung bisa menjadi sumber masalah dari kegagalan kinerja implementasi kebijakan. Karena sebab itu, upaya pelaksanaan kebijakan memberi syarat keadaan lingkungan luar yang mendukung.

Kegiatan implementasi suatu kebijakan tidak akan bisa berlangsung dengan baik tanpa adanya sumber daya yang dibutuhkan dalam proses implementasi kebijakan. Sumber daya adalah salah satu faktor yang berarti dalam melakukan kebijakan publik. Sumber daya yang penting meliputi staf yang mencukupi serta keahlian - keahlian yang baik untuk melakukan tugas-tugas mereka, informasi, wewenang serta fasilitas yang dibutuhkan untuk menterjemahkan pendapatpendapat diatas kertas agar bisa melakukan pelayanan-pelayanan publik

Sumber daya yang dibutuhkan dalam implementasi kebijakan itu meliputi sumber daya manusia, sumber daya keuangan/anggaran, dan sumber daya peralatan (gedung, peralatan, tanah, dan sebagainya). Tapi dari ketiga sumber daya tersebut yang paling penting adalah sumber daya manusia karena tanpa adanya manusia maka sumber daya - sumber daya yang lain tidak dapat di dapatkan, tetapi sumber daya manusia pun harus cukup jumlah orang yang dibutuhkan dan juga mempunyai keahlian yang cukup.

Kurangnya tenaga ahli dalam pengelolaan sampah, kurang ketertarikan para kader pengelolaan sampah, dan kurangnya anggaran untuk pengelolaan sampah. Selanjutnya kurangnya sarana prasarana seperti armada pengangkut sampah, TPSS, kurang optimalnya Pemerintah memberikan motivasi untuk memberdayakan masyarakat dalam pengelolaan sampah, anggaran dari APBD sangat minim, belum sadarnya masyarakat Kecamatan Tawang membayar retribusi sampah.

\section{Kesimpulan}

Implementasi Kebijakan akan berhasil dan tidaknya di implementasikan tergantung oleh variable-variabel bebas yang akan menuntun dalam mencapai prestasi kerja, hal ini seiring dengan apa yang di katakan oleh (Abdul Wahab, 2008) yaitu Jalan yang menjadi jembatan diantara kebijaksanaan serta prestasi kerja dipisahkan oleh sejumlah variabel bebas (independent variable) yang memiliki ikatan yaitu Ukuran dan tujuan kebijaksanaan, Sumber-sumber kebijaksanaan, Karakter serta sifat Lembaga/Instansi pelaksanan, Komunikasi diantara organisasi terikat dan aktivitas- 
aktivitas penyelenggara, Sikap para pelaksana serta Lingkungan ekonomi, sosial serta politik. Prestasi kerja yang dimaksud dalam hai ini adalah terimplementasinya kebijakan tentang pengelolaan sampah yaitu Peraturan Daerah Nomor 7 Tahun 2012 Tentang Pengelolaan Sampah oleh dinas Lingkungan Hidup khususnya di wilayah Kecamatan Indihiang Kota Tasikmalaya.

Dinas Lingkungan Hidup dalam mengimplementasikan Peraturan Daerah Nomor 7 Tahun 2012 Tentang Pengelolaan Sampah harus membuka komunikasi secara terbuka kepada masyarakat dengan mensosialisasikan peratauran tersebut melalui pengajian, acara informal seperti dalam acara Jumat bersih (Jumsih) dan Dinas Lingkungan Hidup harus intens dan lebih ditingkatkan koordinasi dengan instansi lainnya, terutama dengan Dinas Kesehatan, SATPOL PP karena instansi ini adalah sebagai penegakan Peraturan Daerah tersebut sesuai dengan Standard Operating Prosedures (SOP). Dinas Lingkungan Hidup harus intens melakukan pengawasan dan pembinaan terhadap para pelaksana di lapangan dan memberikan fasilitas sarana prasarana yang cukup untuk mengelola sampah dan memberikan motivasi seperti bonus dan lain sebagainya. 
Muhammad Ibrahim Sahupala

\section{BIBLIOGRAFI}

Abdul Wahab, S. (2008). Analisis Kebijakan: Dari Formulasi ke Implementasi Kebijakan Negara Edisi Kedua. Bumi Aksara. Jakarta.

Agustino, L. (2006). Politik dan Kebijakan publik. AIPI Bandung.

Hidayat, B., \& Ahza, A. B. (n.d.). Sugiyono. 2007. Karakteristik Tepung Ubi Jalar (Ipomoea Batatas L.) Varietas Shiroyutaka Serta Kajian Potensi Penggunaannya Sebagai Sumber Pangan Karbohidrat Alternatif.

Muslih, M. (2016). Pengaruh Lingkungan Keluarga Dan Lingkungan Sekolah Terhadap Prestasi Belajar Siswa Kelas 6 SDN Limbangan. Syntax Literate; Jurnal Ilmiah Indonesia, 1(4), 41-50.

Nasution, I., \& Agustinus, R. (2006). Restorasi Pancasila: Mendamaikan Politik Identitas dan Modernitas. Bogor: Brighten Institute.

Parsons, W. (2006). Public Policy: An Introduction to The Theory and Practices of Policy Analysis, diterj Tri Wibowo: Public Policy: Pengantar Teori dan Praktik Analisis Kebijakan. Jakarta: Kencana.

Sulaeman, E., Udall Jr, J. N., Brown, R. F., Mannick, E. E., Loe, W. A., Hill, C. B., \& Schmidt-Sommerfeld, E. (1998). Gastroesophageal reflux and Nissen fundoplication following percutaneous endoscopic gastrostomy in children. Journal of Pediatric Gastroenterology and Nutrition, 26(3), 269-273.

Tachjan, D. H. (2006). Implementasi Kebijakan Publik Cetakan 1. Bandung.

Van Meter, D. S., \& Van Horn, C. E. (1975). The policy implementation process: A conceptual framework. Administration \& Society, 6(4), 445-488.

Widodo, J. (2007). Analisis kebijakan publik: Konsep dan aplikasi analisis proses kebijakan publik. Malang: Bayumedia Publishing. 